\title{
A Role for Startups in Unleashing the Disruptive Power of Social Media
}

\author{
Antonio Ghezzi* \\ Politecnico di Milano - Department of Management, Economics and Industrial Engineering \\ Via Lambruschini 4B, 20156 Milan - Italy \\ antonio1.ghezzi@polimi.it \\ Luca Gastaldi \\ Politecnico di Milano - Department of Management, Economics and Industrial Engineering \\ Via Lambruschini 4B, 20156 Milan - Italy \\ luca.gastaldi@polimi.it \\ Emanuele Lettieri, \\ Politecnico di Milano - Department of Management, Economics and Industrial Engineering \\ Via Lambruschini 4B, 20156 Milan - Italy \\ emanuele.lettieri@polimi.it \\ Antonella Martini, \\ University of Pisa, \\ DESTEC \\ L.go L. Lazzarino, 2, 56122 Pisa - Italy \\ a.martini@unipi.it \\ Mariano Corso \\ Politecnico di Milano - Department of Management, Economics and Industrial Engineering \\ Via Lambruschini 4B, 20156 Milan - Italy \\ mariano.corso@polimi.it \\ * Corresponding author
}

CITE AS

Ghezzi A., Gastaldi L., Lettieri E., Martini A., Corso M. (2016), “A role for startups in unleashing the disruptive power of social media", Int. J. of Information Management, forthcoming

\section{HIGHLIGHTS}

- Literature has paid little attention to new sources of social media innovation

- Analyzing social media startups helps drawing the field's innovation paths

- Social media startups are more focused on pure social network services

- Social media management is emerging as key area for social media startups

- Social media startups often develop open innovation relations with incumbents

\section{KEYWORDS}

Social Media, Startups, Disruptive innovation, Startup-driven innovation 


\section{ABSTRACT}

As social media attract increasing attention from executives and find varied applications in different industries and fields of practice, research on the subject has been investigating the antecedents, moderators, mediators and outcomes of social media adoption, as well as impacts on the organizational and individual level. However, relatively little attention has been paid to the discussion of the new sources of social media innovation - i.e., the upstream originators of social media solutions. Such innovations of a possibly disruptive nature often originate from startups, which can constitute a significant driver for Social Media development and can influence the adopting incumbents' behaviors. This study aims at shedding first light on social media-based solutions developed and delivered by startups. By surveying the Crunchbase database, we identified 724 funded social media startups, which were further classified into six categories, namely: (i) social network; (ii) social commerce; (iii) social recruitment; (iv) social management; (v) social loyalty and advocacy; (vi) contact management. Our findings show how the large majority of startups deliver social network solutions to incumbents, followed by social media management applications. The findings also shed light on emerging approaches to value generation and open innovation from social media related to and driven by startups.

\section{INTRODUCTION}

Social media have radically transformed and are continuously transforming the way we, as individuals and professionals, communicate, collaborate, consume and create (Aral et al., 2013).

As social media are exploding in popularity among consumers, companies seek to extract value from these solutions in order to innovate their business models and managerial practices (Luo et al., 2013). In the last years, several authors (e.g., Enders et al., 2008; Kietzmann et al., 2011) remarked how companies have paradigmatically changed the way they are organized and managed, as well as how they compete. The broad social media practice embeds a number of new tools and approaches that have the potential to support or enhance these strategic, organizational and managerial modifications (Ngai et al, 2015).

In fact, these radical-and probably not reversing-changes affecting modern completion are driven by an increasing embeddedness of companies in the "social" environment, which goes beyond inter-firm relationships (e.g., see Uzzi, 1997) and growingly encompasses interactions with end users (Gallaugher \& Ransbotham, 2010). As a result, we urgently need to update our current understanding of the disrupting power of social media, as well as the nurturing of a scientifically-based and empirically-relevant debate about whether and how executives could extract value out of them (e.g., Kietzmann et al., 2011). In this regards, a missing link emerges.

The social media phenomenon arose as an applied paradigm for communication and networking among individuals, with a limited or fuzzy theorization backing it (Ngai et al., 2015). A wide part of our current understanding is based on anecdotal evidence, grey literature or unproved assumptions. Additionally, the on-going theoretical effort is more devoted to investigate specific examples of social media (e.g., Facebook, Twitter, Pinterest, Wikipedia) rather than developing new interpretative lenses, and establishing clear guidelines for managers on how to collectively use them (Aral et al., 2013).

This confirms the need to crystallize the lessons learnt and provide executives with clear guidelines about whether and how they should develop a social media strategy for their organizations, thus underscoring the practical implications, the pragmatic tradeoffs, the activation triggers and the decisional 
levers they should take into account. In particular, there is urgency for studies with a strong theoretical foundation that might offer a lasting guidance within a phenomenon that evolves dramatically on a daily basis. Executives from different industries (e.g., Kaplan \& Haenlein, 2010; Kim \& Ko, 2012) are puzzled by the lack of such knowledge, which could severely jeopardize the fruitful exploitation of this new relationship with end customers as well as other key stakeholders.

More specifically, the extant research on social media has been placing its focus on how large-size companies or incumbents in the one hand, and users or customers on the other hand, adopt and use social media (Aral et al., 2013). Therefore, the literature has been dealing with the investigation of antecedents, moderators, mediators and outcomes of social media adoption, as well as its impacts on the organizational and individual level (Ngai et al., 2015). However, relatively little attention has been paid to the discussion of the new sources of social media innovation-i.e., the upstream originators of social media solutions, tools, services and applications (Boyd, 2007).

While a share of such solutions come from large-size IT vendors and may be embedded or integrated as addson within their consolidated systems, a significant momentum to innovation in social media is given by new ventures or startups which develop and deliver a plethora of original products and services with varied applications. These startups aimed at jumping onto the social media hype, but, given their flexible, creative and lean strategic approach (Blank, 2013), may constitute a significant driver for the field's growth and development, with clear influences on incumbents' behaviors. Startups may hence trigger social media innovations that are truly disruptive in nature (Downes \& Nunes, 2013).

Against this background, this study aims at narrowing this gap by crystallizing original evidence about startups' role as innovation enablers for social media, by means of an in-depth analysis of the applications offered by startups in the social media realm. By identifying and discussing the main application domains, the paper will shed first light on the current and future streams of innovation in social media, thus pointing at future research directions while providing practitioners with guidelines on the innovation paths they should follow to integrate or complement their social media efforts.

\section{LITERATURE REVIEW}

As the field of research and practice evolves, definitions of social media vary widely. Historically, social media was first referred to as "Web 2.0" by Tim O'Reilly and Dale Dougherty in 2004. Later on, Web 2.0 was gradually replaced by the term "social media" to underscore the role of social interactions in the plethora of channels, tools and platforms that Web 2.0 accounted for (Corso et al., 2013). Coherently to this evolution, social media have been defined as the social interaction among people in which they create, share or exchange information and ideas in virtual communities and networks (Ahlqvist et al., 2008). According to Kaplan and Haenlein (2010, p. 61), social media is "a group of internet-based applications that build on the ideological and technological foundations of Web 2.0, and that allow the creation and exchange of user generated content".

As an increasing number of companies in different industries and competitive settings valued interactions and collaborations with users or customers, social media were increasingly acknowledged as a highly promising set of tools and approaches to connect and share information with third parties (Ngai et al., 2015) or with own employees (Leonardi et al., 2013). Also, social media have been instrumental in establishing networking competencies, in helping firms performing better (Chiu, 2009) and in challenging existing 
marketing and customer relationship practices, such as customer service and promotional processes (Zeng, 2014). As a result, companies' executives in a variety of industries (Sashi, 2012) have become increasingly convinced of the value of harnessing social media to improve and ultimately transform their business (Divol et al., 2012).

Notwithstanding the paramount increase in the attention paid to social media by executives and in turn researchers, a certain ambiguity in the definition, the boundaries and the impacts of this phenomenon still exists (Leung et al., 2013). The research streams associated to this broad term are also varied, reflecting the pervasiveness of its means, meanings and objectives (Tess, 2013).

A recent literature review (Ngai et al., 2015) concluded that social media covers a wide range of research topics, crosscutting three major research theories, namely: personal behavior theories, social behavior theories and mass communication theories, which in turn may be split into thirty-one different sub-streams of research, the most widely referred to being: technology acceptance, social capital theory, social identity theory, social influence theory, uses and gratifications theory, personal traits theory, theory of planned behavior, social cognitive theory, expectation and disconfirmation paradigm, social exchange theory and social network analysis.

Ngai et al. (2015) hence develop the causal-chain framework for social media research depicted in Figure 1, which identifies the inter-relationships of different research dimensions and constructs linking to causes and results of users' behavior in the adoption of social media. Antecedents of users' behavior refer to social factors (e.g., social capital), users' attributes (e.g., user personality) and organizational attributes (e.g., marketing orientation). Users' behavior is also mediated by platform attributes (e.g., tool integrity), social factors (e.g., social influence) and users' attributes (e.g., user behavior), while it is moderated by user characteristics (e.g., user personality) and social factors (e.g. social influence). Outcomes affect both the personal context (e.g. user intention) and the organizational context (e.g., customer relationship).

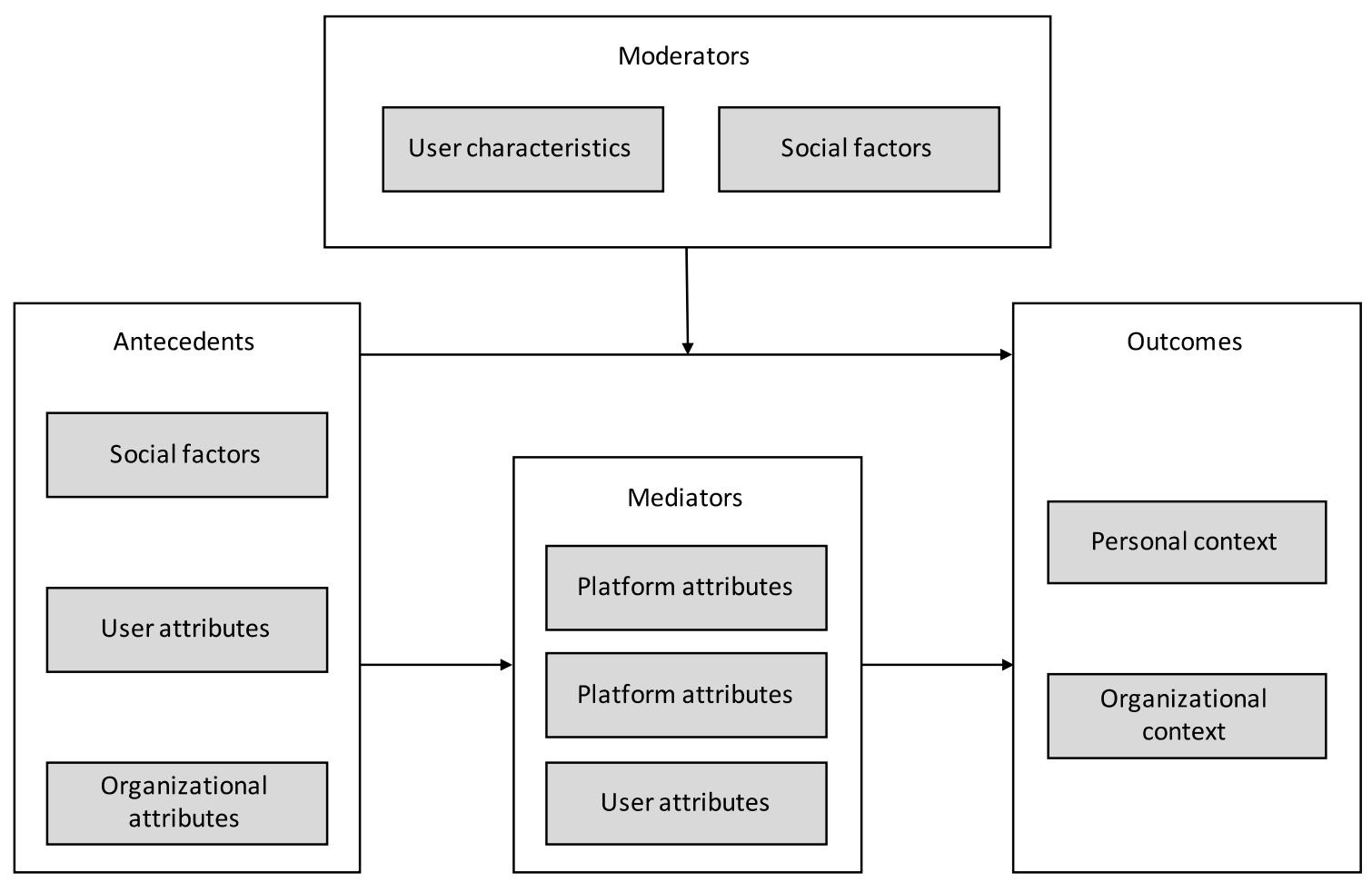

Figure 1. Causal-chain framework for social media research (adapted from Ngai et al., 2015) 
Such framework helps shedding light on the multifaceted impacts of social media-both at an individual and organizational levels.

Kietzman et al. (2011) divided social media's features and functionalities into seven blocks:

1. Identity: is the extent to which users reveal themselves by adjusting data privacy control or using tools for self-promotion;

2. Reputation: it is the extent to which users can identify the social standing of others in social media settings;

3. Relationship: is about the relations between users; two or more users may have something in common that connect them, like the same friends or favorite music;

4. Presence: is about giving possibility to check whether other users are available, e.g. willing to talk or not;

5. Sharing: represents the extent to which users exchange, distribute, and receive content; as a whole, it is a measure of how "social" users or customers are;

6. Conversation: it is the extent to which users communicate with each other and implies different communication formats and protocols for both users who wish to use specific social media tools and firms who seek to host and track such conversations;

7. Groups: represent the extent to which users are ordered or form communities-defining membership rules and protocols to be followed in the various communication activities.

Utilized individually or together, these blocks can help mangers making sense of the social media ecology, and better understanding both their audience as well as their engagement needs (Kietzman et al., 2011).

Another interesting categorization is the one bases on social media functionalities. From this viewpoint, researchers have explored possible applications as well as business impacts on companies. The various contributions can be grouped into five main research streams.

A first one refers to the creation and exploitation of communities of users by means of social networks, defined by Ellison (2007, p. 210) as "web-based services that allow individuals to construct a public or semipublic profile within a bounded system, articulate a list of other users with whom they share a connection, and view and traverse their list of connections and those made by others within the system". Leveraging social network sites can be possibly valuable for a number of reasons, including product development (e.g., Roberts \& Candi, 2014).

A second stream refers to social commerce, a form of commerce mediated by social media (e.g., see Wang \& Zhang, 2012) in which sellers - who can be both individuals and firms-are connected in online social networks (e.g., see Stephen \& Toubia, 2010). In this field, studies have alternatively focused on: individual motives (Snyder et al., 1997); social support and relationship quality (Liang et al, 2011); consumer's trust and trust performance (Kim \& Park, 2013); and design features at an individual, conversation, community and commerce level (Huang \& Benyoucef, 2013).

A third stream is labeled as social recruitment, which discusses the potential role social media might play as a recruitment tool to support the human resource department (e.g., see Doherty, 2010). This possibly promising area is still under-investigated in the innovation management and information systems research.

A fourth stream focuses on the analysis, management and prediction of social media users' behavior (e.g., see Ansari et al., 2011, Tan et al., 2011; Stieglitz \& Dang-Xuan, 2013) as well as on social media-related content that a company might deliver through or extract from social platforms (e.g., see Kaplan \& Haenlein, 2010; Kietzman et al., 2011). 
A fifth stream refers to social marketing, defined as the exploitation of social media within broader marketing efforts paid by a company, including the creation of brand reputation, loyalty and customer advocacy (e.g., see Erdoğmuş \& Cicek, 2012; Laroche et al., 2012; Laroche et al., 2013; Venkateswara et al., 2014), the use of social media as part of the promotion and advertising mix (e.g., see Mangold \& Faulds, 2009; Fournier \& Avery, 2011) and its inclusion in the Customer Relationship Management (CRM) process (e.g., see Heller Baird \& Parasnis, 2011). With respect to CRM, past studies confirmed contact management as a salient issue in exploiting social media (Gallaugher \& Ransbotham, 2010; Yates \& Paquette, 2011).

When discussing the outcomes and impacts of the abovementioned applications of social media, the extant literature focuses on the organizational and the individual levels (Ngai et al., 2015). Although the two spheres are tightly intertwined, they lead to specific findings.

At the organization level, social media allow people to connect, share information, and participate in all business processes. Positive results can be achieved only through proper training and control of those users and employees who are in charge to use companies' social media platforms or to gather customer-related information (Kaplan \& Haenlein, 2010; Martini et al., 2013). An interesting debate is still ongoing about of the relationships between social media and marketing and branding activities (Laroche et al., 2013). Brands rushed into social media, viewing social networks, video sharing, online communities, and microblogging sites as a panacea for decreasing investments while increasing returns compared to traditional brand building routes (Fournier \& Avery, 2011). Still, the use of social media may backfire, as it may create reputation risks that jeopardize a company's brand (Laroche et al., 2013; Venkateswara et al. 2014).

At the individual level, social media offer the opportunity to break communication barriers and help people expanding their social circles (Nhai et al., 2015). However, notwithstanding these positive impacts, possible drawbacks may be associated to the use of these tools and instruments, such as:

- The decrease of real-life interactions and the subsequent impoverishment of actual experience as social media replace other face-to-face, less-mediated communication channels (Hanna et al., 2011);

- The negative effects of social media usage, like the so called "social overload" determined by an excessive use of and reliance on technological tools, thus leading to social exhaustion or the intention to discontinue social media use (Maier et al., 2014);

- The risk that a wrong usage of social media could bring tensions among the employees within a company, where a bad reputational impact may lead to distrust on colleagues and bosses (Venkateswara et al., 2014);

- An excessive reliance on social media-related information may create perception biases, as a person could base his thoughts only on the basis of social media reputation, avoiding the real knowledge of colleagues' strengths and weaknesses (Nagedra, 2014).

Past research on social media investigated several areas, reviewing various application fields and outcomes, at both an individual and an organizational level. Yet, while at an individual level the literature extensively covered antecedents, moderators and outcomes of social media adoption by end users and professionals, at an organizational level it mostly focused on incumbents and large-size companies, thus largely disregarding innovations stemming from new ventures or startups offering original solutions. This limitation puzzles our understanding about the actual capability of social media to disrupt current business models and services through the blue-ocean vision of innovative startups (Kim \& Mauborgne, 2005). In this regard, shedding first light on the relationship between incumbents and startups would help understanding the evolution dynamics within the social media arena, by disclosing sources of social media-related disruptive innovations, coming from startups rather than incumbents themselves. 


\section{METHODOLOGY}

This study aims at shedding first light on social media-based solutions developed and delivered by startups. In this view, the identification and surveying of the different solutions were performed by leveraging and combining secondary sources of information. More specifically, raw data on international startups active in the social media domain were collected from Crunchbase (www.crunchbase.com): an online database collecting data on the startups ecosystem, with specific reference to startups and entrepreneurs' profiles, financing rounds and events. Crunchbase has already been used in published scientific studies as a significant and comprehensive source of startups-related content (e.g., see Block \& Sandner, 2011; Werth \& Boeert, 2013).

The following inclusion criteria have been defined to select the most interesting startups active in the social media domain:

- Year of funding: only the startups funded after 2010 have been considered;

- External funding: only the startups funded by institutional investors (i.e. venture capitals), incubators, family offices, club deals and business angels have been considered.

These criteria allowed to select the most recent startups, which may indeed lead innovation in the field; at the same time, only funded startups were selected as funding is traditionally considered an accreditation and positive assessment of the novelty, viability and of the business model backing the startups' business idea. The use of these criteria allowed to identify 724 startups.

To enable their classification in terms of the solution they offer and the related innovation stream they move along, we considered the application streams defined by the existing literature, and we elaborated an operational definition or specification for each of them. Informed by the extant literature on the subject, we classified social media startups on the basis of their field of application and objectives. This classification gives rise to six categories.

1. Social network: solutions connecting groups of individuals possibly showing various commonalities and affinities;

2. Social commerce: solutions enabling the selling of products and services on the main social media or perform a redirecting towards eCommerce platforms starting from the content published in those social media;

3. Social recruitment: solutions aiming at leveraging the information base published in social media to identify promising candidates who may cover companies' open position;

4. Social management: solutions supporting companies in interpreting their users' behaviors in social media and act accordingly, while managing content to publish in those social media;

5. Social loyalty and advocacy: solutions aiming at actively involving customers in the company's marketing activity, by means of sharing comments and content over social media;

6. Content management: solutions allowing to manage customer relationship (both current customers and prospects) though social media channels.

These categories will be employed to present the study's results.

Additionally, all information available from secondary sources about the innovative solutions developed by the selected startups have been collected and analyzed. The identified solutions have been referred to the 
six domains detailed above to provide an overview of how startups are expected to generate value through social media.

\section{RESULTS}

As depicted in Figure 2,67\% of the startups (488 out of 724 ) considered in this analysis offer pure social network services. Although this category is the most populated one, a very limited amount of startups actually reached the necessary critical mass to make it appealing as a business platform where companies and advertisers may invest. Some of these startups, which operate in market niches, showed interesting figures in terms of users and performance, although their business model is still unclearly defined. Considering the whole range of startups offering pure social network services, it is interesting to note that:

- The majority of these startups (203 out of 488 ) are active in vertical domains such as sport (e.g., Sqor Sports, Fan Kave) or music (e.g., Muzooka, Sensbeat);

- The second largest group (133 startups) offer generalist social networks, with no defined target of reference (e.g., Zhihu);

- 94 startups are specialized in photo- and video-sharing (e.g., Snapchat);

- 33 startups offer platforms enabling users' interactions within a local area (e.g., city, neighborhood) or provide highly geo-localized information and content (e.g., Nextdoor);

- A limited number of startups (25) are focused on corporate social networking (e.g., Pie) or social TV devoted to increase the interactions with a television show's audience (e.g., Vyu).

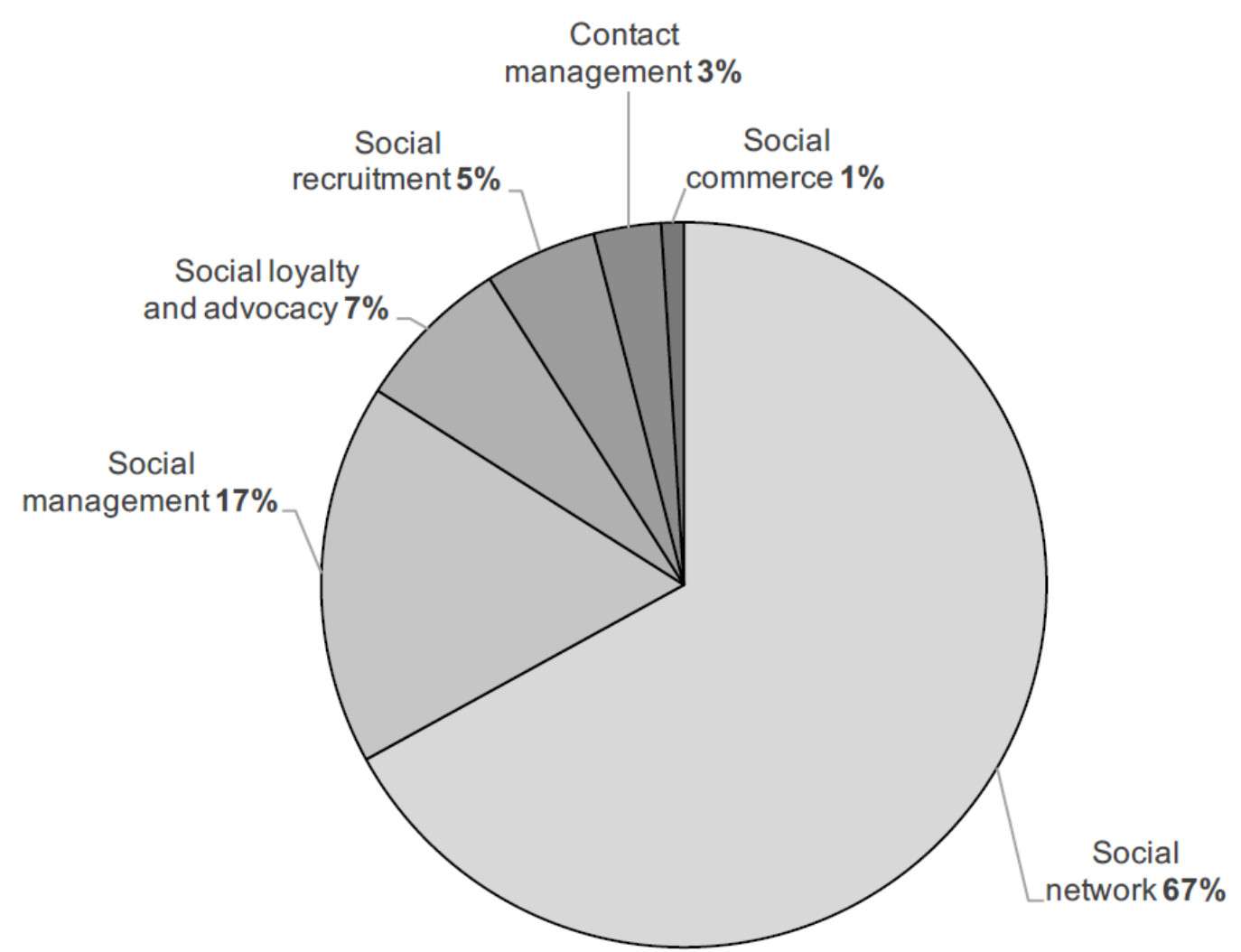

Figure 2. Distribution of the international startups active in the social media domain 
The startups in the social management segment account for the $17 \%$ (124 out of 724 ) of the overall number of startups considered. These startups are almost equally subdivided into three groups. The first one (43 startups) provides analytics and reporting services to monitor the performance of the activities accomplished by users on social media (e.g., Kinetic Social). The second one (38 startups) accomplish sentiment analyses, providing services to interpret and predict user satisfaction and appreciation on any given topic, product or event on the basis of their behavior on the social media (e.g., Banjo). The interpretation of data from users and customers may support both the company's communications and product/service development, as well as improving the business service level. Finally, the third group (43 startups) is specialized in content and curation management, by respectively helping firms managing their webpages (e.g. Epoxy) or in embedding user-generated contents from social media within these webpages (e.g. Related Noise).

The startups in the remaining categories represented in Figure 2 are significantly less diffused, and offer solutions that span from social loyalty and advocacy (e.g., Trapit) to social recruitment (e.g., ZipRecruiter), from contact management (e.g., Engagor) to social commerce (e.g., Easy Social Shop).

As depicted in Table 1, the startups in the social network are those that have received, on average, the highest amount of funding (6.3 million USD). However, this result is highly influenced by the first two players, namely Snapchat (roughly 1.4 billion USD) and Nextdoor (210 million USD). Without these two startups, the average value of funding would be reduced to slightly more than 3 million dollars.

Table 1. Descriptive statistics on the investments in the international startups active in the social media domain

\begin{tabular}{llll}
\hline Category & Min $^{*}$ & Average $^{*}$ & Max $^{*}$ \\
\hline Social network & 0 & 6.3 & 1,386 (Snapchat) \\
\hline Social management & 0 & 4.9 & 121 (Banjo) \\
\hline Social recruitment & 0 & 3.5 & 63 (ZiRecruiter) \\
\hline Social commerce & 0 & 2.2 & 5 (Soldsie) \\
\hline Social loyalty and advocacy & 0 & 1.8 & 20 (Trapit) \\
\hline Content management & 0 & 1.3 & 2.5 (Egagor) \\
\hline Total & $\mathbf{0}$ & $\mathbf{5 . 3}$ & $\mathbf{1 , 3 8 6}$ (Snapchat)
\end{tabular}

The second group of startups for received funding are active in the social management segment, and, on average, these startups have received 4.9 million USD. With 121 million USD, only Banjo can be considered an outlier in the category.

On average, the startups offering social recruitment service received 3.5 million USD. The average investment in this segment would be 1.4 million USD if one would exclude ZipRecruiter, which received 63 million USD.

All the other startups collected less interest from the investors:

- Social commerce startups received on average 2.2 million USD, with Soldsie e Comr.se emerging with respectively 5 and 3.2 million USD;

- The startups active in the social loyalty and advocacy segments received on average 1,8 million USD; among these startups, Trapit has received 20 million USD; 
- Contact management startup received 1.3 million USD; with 2.5 million USD, Engagor is the most funded startup in this segment.

For each one of the six functional group characterizing the analysis, Table 2 reports some distinctive features that are enabled by the startups active in the domain. These features allow understanding the potential development over which it would be interesting to invest in order to really unleash the disrupting power of social media.

Table 2. Distinctive innovative features of the international startups active in the social media domain

\begin{tabular}{lll}
\hline Category & Distinctive features & Example \\
\hline \multirow{2}{*}{ Social network } & User profiling & Kakaxi \\
\cline { 2 - 3 } & Proximity marketing & CO Everywhere \\
\cline { 2 - 3 } & Employee engagement & Shibumi \\
\hline \multirow{2}{*}{ Social management } & Sentiment analysis & Ditto Labs \\
\cline { 2 - 3 } & Cluster analysis & Affinio \\
\hline \multirow{2}{*}{ Social loyalty and advocacy } & User content creator & Tagkast \\
\cline { 2 - 3 } & Gamification & Chripify \\
\hline \multirow{2}{*}{ Social recruitment } & Data mining & Work4 \\
\cline { 2 - 3 } & Social referring & Peercisely \\
\hline \multirow{2}{*}{ Contact management } & Influencer scouting & SocialRank \\
\cline { 2 - 3 } & Lead generation & Reach7 \\
\hline Social commerce & New sale channel & Shopsy \\
\hline
\end{tabular}

Most of the startups offering pure social network services strive to surpass specific critical masses of actively engaged users in order to become interesting platforms for the brands aiming at reaching a peculiar targetboth vertical and generalist. To achieve these results, startups invest in user profiling (e.g., Kakaxi), i.e. the progressive collection of key information describing user behaviors in social media. Another interesting feature allowing social network startups to generate huge amounts of value is the exploitation of georeferencing technologies in order to activate proximity marketing campaigns to be offered to local operators. An interesting example from this viewpoint is CO Everywhere. Finally, a third important distinctive feature offered by social network startups is the enhancement of communication and knowledge sharing-especially among the employees of a firm. Shibumi is quite effective from this viewpoint.

The most innovative social management startups develop solutions to efficiently and effectively handle the relationships with all contacts present within the social media, and support companies in the progressive creation of a social CRM system of their customers. In order to accomplish this goal, two appear as the most promising services over which focusing the generation of value. On the one hand, some startups specialize in sentiment analysis, deepening how consumers perceive a product or service through the real time analysis of consumer actions on social media (e.g., Ditto Labs). On the other hand, other startups exploit data collected from social media in order to create smart audience clustering allowing highly tailored contents (e.g., Affinio).

The startups in the "social loyalty and advocacy" segment seams to generate most of their value when they support companies in the exploitation of users as content creators - pushing them to create contents related to the company's products/services and to deliver them through their social network profiles, so at to generate word-of-mouth dynamics, without receiving any specific reward or prize for it (e.g., Tagkast). 
Alternatively, startups try to engage users through "gamification" mechanisms, getting them to share company's brand-related content on social media through social reward systems that progressively transform users in brand ambassadors (e.g., Chripify).

The core aspect of the startups offering social recruitment services is the exploitation of social media to directly collect professional career-related information on interesting profiles, thus supporting companies' head hunting, selection and recruiting activities. In order to achieve these results, the most innovative startups in this field focus on reducing the cost and the time necessary to accomplish these activities through the development of sophisticated data-mining techniques (e.g., Work4) and/or by exploiting social referring, i.e. leveraging on the so-called "wisdom of the crowds" in order to achieve information regarding the capabilities of a peculiar prospect (e.g., Peercisely). Of course these two strategies are not alternative.

The startups active in contact management offer two distinctive services. The first one is mainly aimed at scouting influencers, i.e. identifying potential brand ambassador among the followers of a firm or its fans on a social media (e.g., SocialRank). The second one is based on lead generation, and generates value by creating strong relationships with prospects active in a social media. An example of a startup operating in this category is Reach7.

Social commerce startups enable the selling of products and services via consolidated social networks. Many of these initiatives tend to do not directly sell from the partnering social network platforms, but operate through a redirecting of customers towards merchants' eCommerce websites. This redirect of web traffic is accomplished thanks to both corporate fan pages (e.g., Easy Social Shop) as well as pictures and videos (characterized by a stronger and immediate impact on users) to easily present the products and services in their portfolio (e.g., Shopsy). The main challenge that is pursed by all these startups is to overcome the natural users' aversion to advertising and promotion messages appearing in social networks, which are mostly perceived as entertainment environments.

\section{DISCUSSION AND CONCLUSIONS}

Our findings shed first light on startups' behaviors for innovation through the exploitation of social media. Our findings complement and enrich what is already known about incumbents' behaviors, thus uncovering possible research gaps as well as strategies and practices that still find little diffusion and adoption within incumbents and big companies.

Findings will be discussed along two main directions in the followings. First, startups' actual strategies will be discussed with respect to the studies on incumbents and individuals presented during the review of the literature. Second, emerging approaches to value generation from social media will be discussed with particular attention to startups.

Results show that $67 \%$ of social media startups developed pure social network services. This preference confirms that startups aim at offering solutions that address incumbents' explicit needs in terms of social interactions with end customers and other relevant stakeholders to increase the likelihood to generate revenues in the short-term. Although this percentage could be inflated in our sample because of the selection of funded startups, our results confirm that startups act within an open innovation framework (Chesbrough, 2004; Christensen et al., 2005), developing solutions actually faster than incumbents that are slow in reorganizing themselves to address the challenges. Startups have thus the opportunity to leverage on their 
small size and informal organizational structure to develop innovative solutions that address well-formalized needs.

In this view, it is interesting to point out that among these startups, the large majority (203) developed tailored vertical solutions with the twofold benefit of focusing their efforts (and limited financial resources) on specific needs and increasing the chance of defending themselves from other rival startups. This finding remarks the need to complement past studies about incumbents' strategies on social media because some of them might prefer an open innovation approach by scouting solutions developed by startups rather than exploiting internal capabilities and resources (Chesbrough \& Appleyard, 2007).

Additionally, results show that the second largest group of startups (103) developed generalist social network services. This finding is not against what has been argued so far. When incumbents have not developed clear strategies about how to exploit social media to generate value within their current portfolio of businesses and services, a valuable strategy for startups is developing a solution that addresses individuals' emerging needs about social interactions and prove to incumbents their value.

This reinforces the need of extending what we know about antecedents and consequences of social media at the individual-level. Social media are reshaping how individuals interact among themselves and with companies, and thus scholars of information management and practitioners require clear guidelines about which individual-specific or society-driven factors might facilitate or hinder individuals' willingness to accept social media as mediated channels for social interaction and then engage in their actual use.

The second line of discussion deals with how startups aim at generating value from social media. As shown, social management is the second area for relevance just after social network services. This finding suggests that startups are anticipating - and contributing to - the expected trend about Big Data. While in past years, the main focus for companies has been the development of technological solutions to enable the collection and sharing of extensive amounts of data, value generation is expected to come from their analysis in the very next years.

Sentiment analysis, lead generation, content enrichment, and so on, are emerging as significant opportunities for startups for generating value. Managers need to make sense of data collected from social media to inform their decision-making. In this regard, professional bodies such as CIMA-Chartered Institute of Management Accountants - have promoted a number of initiatives in the last years to develop analytics able to generate relevant information for managers. This need is confirmed by recent literature reviews (e.g., see Hashem et al., 2015) on Big Data that pointed out that past studies focused more on data collection rather than on information generation for decision-making. With this respect, startups anticipate the emerging needs of both society and incumbents.

This study has some limitations that pave the way for further researches on the role that social media might play to disrupt value generation and dynamic business ecosystems as we know them today. First, data are all collected from secondary sources. Although the reputation and reliability of Crunchbase, the availability of data from primary sources - such as through vis-à-vis interviews with or surveys to founders or funders could have helped understanding both the rationale and the expectations that leaded to what we have found, in particular about those uses of that have been argued to grow in the very next years.

Second, although the study benefited from assuming an international scope, the evolution dynamics of different social media might be affected by country-specific factors, such as cultural or normative factors. As extreme example, social media have been claimed to have the capability to reshape the patient-physician 
relationships as well as the whole healthcare ecosystem (Kallinikos \& Tempini, 2014; Yan \& Tan, 2014). Despite the rhetoric, healthcare is undoubtedly a professional and regulated setting, where normative constraints, such as patients' privacy and physicians' responsibilities about diagnoses and therapies, could limit or postpone the expected disruption of current behaviors and practices (Zanaboni \& Lettieri, 2011). In this view, further research should explore country-specific or industry-specific factors that could facilitate or inhibit value generation through social media.

Third, funding has been used as proxy of the "success" of the social media solutions developed by the startups included in our analyses. Although past research (Cooper et al., 1994; Shepherd et al., 2000) has found that startups' capability to collect funds from institutional investors, venture incubators, business angels, etc. anticipates their capability to generate revenues and profits, further research should confirm this claim through longitudinal studies.

Additionally, further research should investigate the evolution in the business models of startups that are developing social media-based solutions/innovations. In fact, the large majority of the startups included in our sample have still unclear business models, which are expected to evolve in the very next years given the significant dynamicity and volatility of the broad digital industry (Ghezzi et al., 2015).

\section{REFERENCES}

Ahlqvist, T., Bäck, A., Halonen, M. \& Heinonen, S. (2008). Social media road maps exploring the futures triggered by social media (VTT Research Notes 2454). Oulu, Fi: Julkaisija-Utgivare.

Ansari, A., Koenigsberg, O. \& Stahl F. (2011). Modeling multiple relationships in social Networks. Journal of Marketing Research, 48(4), 713-728.

Aral, S., Dellarocas, C. \& Godes, D. (2013). Social media and Business Transformation: A Framework for Research. Information Systems Research, 24(1), 3-13.

Blank, S. (2013). Why the lean start-up changes everything. Harvard Business Review, 91(5), 63-72.

Block, J.H., \& Sandner, P. (2011). Venture capital funding in the middle of the year 2011: Are we back to precrisis boom levels?. Strategic Change, 20(5-6), 161-169.

Boyd, D. (2007). Why youth (heart) social network sites: The role of networked publics in teenage social life. MacArthur foundation series on digital learning-Youth, identity, and digital media volume, 119-142.

Chesbrough, H. (2004). Managing open innovation. Research Technology Management, 47(1), 23.

Chesbrough, H.W. \& Appleyard, M.M. (2007). Open innovation and strategy. California Management Review, 50(1), 57-76.

Christensen, J.F., Olesen, M.H. \& Kjær, J.S. (2005). The industrial dynamics of Open Innovation: Evidence from the transformation of consumer electronics. Research Policy, 34(10), 1533-1549.

Cooper, A.C., Gimeno-Gascon, F.J. \& Woo, C.Y. (1994). Initial human and financial capital as predictors of new venture performance. Journal of Business Venturing, 9(5), 371-395. 
Corso, M., Gastaldi, L. \& Martini, A. (2013). The Role of ICT in the New (Virtual) Working Space: An Empirical Investigation on Enterprise 2.0. In: Lytras, M., Ruan, D., Tennyson, R.D., Ordonez De Pablos, P., Garcia Peñalvo, F.J. \& Rusu, L. (Ed.). Information Systems, E-Learning, and Knowledge Management Research, Berlin, De: Springer-Verlag, pp. 546-556.

Divol, R., Edelman, D. \& Sarrazin, H. (2012). Demystifying social media. McKinsey Quarterly, 2(12), 66-77.

Doherty, R. (2010). Getting social with recruitment. Strategic HR review, 9(6), 11-15.

Downes, L. \& Nunes, P. (2013). Big Bang Disruption. Harvard Business Review, 91(3), 44-56.

Ellison, N.B. (2007). Social network sites: Definition, history, and scholarship. Journal of Computer-Mediated Communication, 13(1), 210-230.

Enders, A., Hungenberg, H., Denker, H.P. \& Mauch, S. (2008). The Long Tail of Social Networking: Revenue Models of Social Networking Sites. European Management Journal, 26(3), 199-211.

Erdoğmuş, i.E. \& Cicek, M. (2012). The impact of social media marketing on brand loyalty. Procedia - Social and Behavioral Sciences, 58(5), 1353-1360.

Fournier, S. \& Avery, J. (2011). The uninvited brands. Business Horizons, 54(3), 193-207

Gallaugher, J. \& Ransbotham, S. (2010). Social media and customer dialog management at Starbucks. MIS Quarterly Executive, 9(4), 197-212.

Ghezzi, A., Cortimiglia, M.N. \& Frank, A.G. (2015). Strategy and business model design in dynamic telecommunications industries: A study on Italian mobile network operators. Technological Forecasting and Social Change, 90(Part A), 346-354.

Haefliger, S., Monteiro, E., Foray, D. \& von Krogh G. (2011) Social Software and Strategy. Long Range Planning, 44(5), 297-316.

Hanna, R., Rohm, A. \& Crittenden, V.L. (2011). We're all connected: The power of the social media ecosystem. Business Horizons, 54(3), 265-273.

Hashem, I. A.T., Yaqoob, I., Anuar, N.B., Mokhtar, S., Gani, A. \& Khan, S.U. (2015). The rise of "big data" on cloud computing: Review and open research issues. Information Systems, 47(1), 98-115.

He, W., Zha, S. \& Ling L. (2013). Social media competitive analysis and text mining: A case study in the pizza industry. International Journal of Information Management, 33(3), 464-472.

Heller Baird, C. \& Parasnis, G. (2011). From social media to social customer relationship management. Strategy and Leadership, 39(5), 30-37.

Huang, Z., \& Benyoucef, M. (2013). From e-commerce to social commerce: A close look at design features. Electronic Commerce Research and Applications, 12(4), 246-259.

Kallinikos, J. \& Tempini, N. (2014). Patient data as medical facts: Social media practices as a foundation for medical knowledge creation. Information Systems Research, 25(4), 817-833.

Kaplan, A.M. \& Haenlein M. (2010). Users of the world, unite! The challenges and opportunities of social media. Business Horizons, 53(1), 59-68. 
Kietzman, J.H., Hermkens, K., McCarthy, I.P. \& Silvestre, B.S. (2011). Social media? Get serious! Understanding the functional building blocks of social media. Business Horizons, 54(3), 241-251.

Kim, S. \& Park, H. (2013). Effects of various characteristics of social commerce (s-commerce) on consumers' trust and trust performance. International Journal of Information Management, 33(2), 318-332.

Kim W.C. \& Mauborgne R. (2015) Blue Ocean Strategy: How to Create Uncontested Market Space and Make the Competition Irrelevant (Expanded Edition). Boston, Ma: Harvard Business Publishing.

Laroche, M., Habibi, M.R. \& Richard M-O. (2013). To be or not to be in social media: How brand loyalty is affected by social media?. International Journal of Information Management, 33(1), 76-82.

Laroche, M., Habibi, M.R., Richard, M.O. \& Sankaranarayanan, R. (2012). The effects of social media based brand communities on brand community markers, value creation practices, brand trust and brand loyalty. Computers in Human Behavior, 28(5), 1755-1767.

Leonardi, P.M., Huysman, M. \& Steinfield, C. (2013). Enterprise social media: Definition, history, and prospects for the study of social technologies in organizations. Journal of Computer-Mediated Communication, 19(1), 1-19.

Leung, D., Law, R., Van Hoof, H. \& Buhalis, D. (2013). Social media in tourism and hospitality: A literature review. Journal of Travel \& Tourism Marketing, 30(1-2), 3-22.

Liang, T.P., Ho, Y.T., Li, Y.W. \& Turban, E. (2011). What drives social commerce: The role of social support and relationship quality. International Journal of Electronic Commerce, 16(2), 69-90.

Luo, X., Zhang, J. \& Duan, W. (2013). Social media and firm equity value. Information Systems Research, 24(1), 146-163.

Mangold, W.G. \& Faulds, D.J. (2009). Social media: The new hybrid element of the promotion mix. Business Horizons, 52(4), 357-365.

Martini, A., Massa, S. \& Testa, S. (2013). The Firm, the platform and the customer: A 'double mangle' interpretation of social media for innovation. Information \& Organization, 23(3), 198-213.

Nabil, S. (2013). Knowledge management in the age of cloud computing and Web 2.0: Experiencing the power of disruptive innovations. International Journal of Information Management, 33(1), 160-165.

Ngai, E.W., Tao, S.S. \& Moon, K.K. (2015). Social media research: Theories, constructs, and conceptual frameworks. International Journal of Information Management, 35(1), 33-44.

Roberts, D.L. \& Candi, M. (2014). Leveraging social network sites in new product development: opportunity or hype?. Journal of Product Innovation Management, 31(S1), 105-117.

Sashi, M.S. (2012). Customer engagement, buyer-seller relationships, and social media. Management Decision, 50(2), 253-272

Shepherd, D.A., Douglas, E.J. \& Shanley, M. (2000). New venture survival: Ignorance, external shocks, and risk reduction strategies. Journal of Business Venturing, 15(5), 393-410.

Snyder, C.R., Cheavens, J., \& Sympson, S.C. (1997). Hope: An individual motive for social commerce. Group dynamics: Theory, research, and practice, 1(2), 107-118. 
Stephen, A.T. \& Toubia, O. (2010). Deriving value from social commerce networks. Journal of Marketing Research, 47(2), 215-228.

Stieglitz, S. \& Dang-Xuan, L. (2013). Emotions and information diffusion in social media: Sentiment of microblogs and sharing behavior. Journal of Management Information Systems, 29(4), 217-248.

Tan, C., Lee, L., Tang, J., Jiang, L., Zhou, M. \& Li, P. (2011). User-level sentiment analysis incorporating social networks. Proceedings of the 17th ACM SIGKDD international conference on Knowledge discovery and data mining (pp. 1397-1405). ACM.

Tess, P.A. (2013). The role of social media in higher education classes (real and virtual): A literature review. Computers in Human Behavior, 29(5), A60-A68.

Uzzi, B. (1997). Social structure and competition in interfirm networks: The paradox of embeddedness. Administrative Science Quarterly, 42(1), 35-67.

Wang, C. \& Zhang, P. (2012). The evolution of social commerce: The people, management, technology, and information dimensions. Communications of the Association for Information Systems, 31(5), 1-23.

Werth, J.C. \& Boeert, P. (2013). Co-investment networks of business angels and the performance of their start-up investments. International Journal of Entrepreneurial Venturing, 5(3), 240-256.

Yan, L. \& Tan, Y. (2014). Feeling Blue? Go Online: An Empirical Study of Social Support Among Patients. Information Systems Research, 25(4), 690-709.

Yates, D. \& Paquette, S. (2011). Emergency knowledge management and social media technologies: A case study of the 2010 Haitian earthquake. International journal of information management, 31(1), 6-13.

Yen Ting H.C. (2008). How network competence and network location influence innovation performance. Journal of Business and Industrial Marketing, 24(1), 46-55.

Zanaboni, P. \& Lettieri, E. (2011). Institutionalizing telemedicine applications: The challenge of legitimizing decision-making. Journal of Medical Internet Research, 13(3), e72.

Zeng, B. \& Gerritsen, R. (2014). What do we know about social media in tourism? A review. Tourism Management Perspectives, 10(1), 27-36.

\section{VITAE}

Antonio Ghezzi, PhD, is Assistant Professor in the Department of Management, Economics and Industrial Engineering of Politecnico di Milano, where he teaches "Strategy and Marketing". His main research field is strategic management, startup strategy and digital strategy theories and models, with a specific focus on business model design and innovation. He is member of the core faculty of MIP - Graduate School of Business (Corporate Strategy Area) and director of the Hi-tech Startup Observatory at Politecnico di Milano.

Luca Gastaldi, PhD, is Assistant Professor in the Department of Management, Economics and Industrial Engineering at Politecnico di Milano, where he teaches "Analysis and Design of Managerial Processes". His research is focused on digital innovation, ambidexterity, smart working and social media. He is the director of the Digital Agenda Observatory at Politecnico di Milano and senior researched in the Digital Innovation in 
Healthcare Observatory. He is member of the core faculty of MIP - Graduate School of Business ("People Management and Organization" area) and board member of the Continuous Innovation Network (CINet).

Emanuele Lettieri, PhD, is Associate Professor at Politecnico di Milano, where he teaches "Accounting, Finance \& Control" and "Healthcare Management". His research interests deal with management innovation and technology strategy in professional and knowledge intensive settings, such as healthcare. He is currently investigating how to design evidence-based decision-making from administrative databases, social media, and wearables. He is the Director of the International Part-Time MBA program at MIP-Graduate School of Business, Politecnico di Milano.

Antonella Martini, PhD, is Associate Professor at the University of Pisa where she teaches "Organization Design" and "Business Management \& Organization". Her main research interests deals with continuous innovation, social media and ambidexterity. She is principal investigator for the 2015 MIT-UNIPI project investigating radical innovations for smart specialization. She is board member of the Continuous Innovation Network (CINet), and president of CIMEA.

Mariano Corso, PhD, is Full Professor in the Department of Management, Economics and Industrial Engineering of Politecnico di Milano, where he teaches "Leadership and Innovation" and "Business Management and Organization". His major research interests and consulting expertise relate to organization, change management and governance of digital innovation. He is member of the core faculty of MIP Graduate School of Business ("People Management and Organization" area) and co-founder and member of the scientific board of the Digital Innovation Observatories of Politecnico di Milano. 